\title{
The efficacy of custodiol as blood cardioplegia for myocardial protection in adult cardiac surgery
}

\author{
Ihab Mohamed Yehya Moursi ${ }^{1}$, Shaban Halawa ${ }^{2 *}$ \\ From World Society of Cardiothoracic Surgeons 25th Anniversary Congress, Edinburgh \\ Edinburgh, UK. 19-22 September 2015
}

\section{Background/Introduction}

Custodiol cardioplegia is attractive method of myocardial protection, as a single dose provides a long period of preservation. Despite widespread use in Europe, the available data confirming its efficacy is little compared with conventional methods of cardioplegia. Custodiol solution is administered in a single-dose, allowing the operation to be done continuously. This is an advantage over other cardioplegic solutions that may have to be re administered every 20-30 minutes.

\section{Aims/Objectives}

Is to compare the efficacy of Custodiol to standard Plegisol blood cardioplegia in adult cardiac surgical cases.

\section{Method}

This study was a single-center retrospective review of prospectively collected data. Adult cardiac surgery cases performed between January 2011 and August 2013 using Custodiol ${ }^{\mathbb{B}}$ were compared to cases using standard Plegisol blood cardioplegia. The endpoints of intraoperative and post-operative were compared including 30-day mortality, hospital readmission, prolonged mechanical ventilation time, and renal failure.

\section{Results}

Of the 100 cases identified, 40 cases used Custodiol and 60 used blood Cardioplegia. Demographics data were similar in both groups with a mean patient age of $60 \pm$ 14.1 years for Custodiol and $66 \pm 10$ years for blood cardioplegia. The average cardiopulmonary bypass time for Custodiol and blood cardioplegia was $122 \pm 60$ and $135 \pm$ 54 minutes respectively. The Custodiol group had a greater incidence of prolonged ventilation ( $>24$ hours),
$20 \%$ versus $15 \%$ respectively, and this approached statistical significance with a $\mathrm{p}$ value of (0.05). Intra-operative blood usage was significantly higher in the Custodiol group compared to the blood cardioplegia group, with $44 \%$ of patients receiving fresh frozen plasma during the operation compared to only $25 \%$ in the blood cardioplegia group $(p=0.005)$. There is no statistically significant difference in 30-day mortality, hospital readmission, and renal failure.

\section{Discussion/Conclusion}

Custodiol is effective for myocardial protection with distinct advantage of long-term ischemic tolerance although the use of custodiol increase the need of fresh frozen plasma during the perioperative period when compared to blood cardioplegia.

\section{Authors' details}

${ }^{1}$ Cardiac Surgery Department, Prince Sultan Cardiac Center, King Khaled Hospital, Al Kharj 11942, Saudi Arabia. ${ }^{2}$ Cardiac Anesthesia Department, Prince Sultan Cardiac Center, Al Hofuf 31982, Saudi Arabia.

Published: 16 December 2015

doi:10.1186/1749-8090-10-S1-A87

Cite this article as: Moursi and Halawa: The efficacy of custodiol as blood cardioplegia for myocardial protection in adult cardiac surgery. Journal of Cardiothoracic Surgery 2015 10(Suppl 1):A87. 